\title{
Same Time Next Year!
}

\author{
Arthur M. Michalek ${ }^{1}$
}

Published online: 9 October 2017

(C) American Association for Cancer Education 2017

I have recently returned from the annual International Cancer Education Conference (ICEC) which was jointly sponsored by the American Association for Cancer Education (AACE) and the Cancer Patient Education Network (CPEN). The ICEC is the premier meeting in North America dedicated to supporting cancer educators to learn best practices for cancer prevention, diagnosis, treatment, and survivorship. The theme of this year's meeting was Solving Cancer Education Challenges through Innovative, Interdisciplinary, Community, and Global Collaboration which highlighted the global perspective of educational issues that cut across the continuum of the cancer experience for patients and their families with a focus on serving the needs of special populations and addressing disparities in cancer care. This Conference is known for presenting new and creative education models that support development and facilitation of interdisciplinary research across the cancer care continuum. The 2017 conference presented an extensive focus on disparities, special populations, genomics, and the use of effective and innovative formats and technologies. By all early reports, this Conference was a resounding success. ICEC has its roots in the annual meeting of the AACE which has been hosting these events for over 50 years. The continuing success of these conferences is that they have maintained true to their original values (dedicated to maintaining and improving all aspects of cancer education to multidisciplinary audiences) and maintaining their relevance (from its earliest focus on organization and curriculum development to this year's meeting with a focus on genomics and diversity).

Arthur M. Michalek

amm3@buffalo.edu

1 University at Buffalo, Buffalo, NY, USA
I can personally attest to the value and relevance of the annual meeting, having attended nearly everyone since the early 1980s. There are others who have attended even longer. The presence of individuals who have attended the same conference for multiple years without fail says a lot about the value of the conference. For those readers who have attended the conference, I am certain that they will attest to its value. For those of you who, for whatever reason, could not attend, there is always next year. I encourage you all to attend your first ICEC or your second, or third, or fifth, or 20th. You may attend the first time for the innovations, but the networking and development of your professional family will keep you coming back year after year. This annual meeting of the family caused me to reminisce about a movie I saw many years ago. It was 1978 and the film was "Same Time Next Year" which starred Alan Alda and Ellen Burstyn in a romantic comedy about a couple who through some chain of events had a liaison and elected to meet the same weekend every year to renew relations. Their relationship lasted for decades during which time they encountered many challenges in their lives and sought counsel from each other. I am not saying that your attendance at these meetings will result in some romantic intrigue, but I can assure you that it will result in collegial relationships developing into fast friendships. Over the years, I have gained greatly from the mentorship and wisdom of others and, perhaps in some small way, helped in the mentorship of others. Each year, we not only reconnect professionally, but also personally. We have shared happy moments such as marriages and births and also supported one another through health challenges and deaths. I hope that attendees at this year's meeting maintain contact with those with whom they met this year throughout the year and the years ahead. One particular AACE member that many of us have learned from is Joe O'Donnell. He has consented to share his experiences with all our readers by authoring the inaugural 
installment of "Conversations with a Master Cancer Educator". A must read!

I will briefly recap some highlights of the meeting for those who missed it in hopes that it will entice you to attend next year's meeting. A number of excellent workshops preceded the official start of this year's meeting covering areas of communication, sexual problems after cancer treatment, strategies for managing unconscious bias, and e-health literacy. Members of the NCI presented a workshop on the R25 funding mechanism. If any readers have an R25, they should definitely attend the ICEC! We anticipate having a report from Dr. Ming Lei on this workshop in the next issue of the Journal. The opening plenary session was presented by Dr. Stan Gerson, Director of the Case Comprehensive Cancer Center. He gave a marvelous talk entitled "Education Across Cancer: Cancer Training for a Global Disease" in which he highlighted the role of cancer education in the mission of a cancer center. His talk was very well received and several commented that it was encouraging to hear a director with such a sincere and dedicated commitment to education. We were also enlightened by Dr. Edith Mitchell, President of the National Medical Association, on Medicare at age 50. She gave a very clear overview of the historical development of Medicare, its various plans, and its importance relative to the diversity of healthcare delivery. Another plenary session involved building biomedical research capacity in low and middle income countries proffered by Dr. Peter Kilmarx. As Deputy Director of the Fogarty International Center, he was able to share his unique perspective given his past experience in international health. Dr. Deborah Mayer presented a plenary session on engaging survivors and moving the cancer moonshot forward. Again, another tremendously insightful presentation. Next year's meeting, from early reports, will be just as, if not more, instructive and inspirational.

In addition to the above plenary sessions, there were many concurrent sessions. Topics ranged from diversity to education issues for healthcare professionals, community-based strategies, patient navigation, delivery of digital patient information, program evaluation, education cancer research issues, health literacy, prevention, and screening, preparing the next generation. A special session was presented by our colleagues from Oman highlighting their experiences in the development of the Oman Cancer Association. Special thanks to Dr. Al Kharusi, his wife Yuthar Al Rawahi, and Dr. Bassim Al Bahrani for sharing their invaluable experiences. Their talks were truly inspirational. Thanks go to Dr. Amr Soliman for arranging this session. Dr. Soliman has played a key role in coordinating reviews of international submissions so much so that he has been appointed Deputy Editor-in-Chief for International Submissions for the Journal of Cancer Education.

I should point out that these annual meetings are not all work (although we are kept very busy). There are plenty of opportunities for coffee klatches, lunchtime chats, and cocktail conversations. A highlight of this year's meeting was the conference dinner at the Rock n' Roll Hall of Fame. Thank you to the Seidman Cancer Center for sponsoring this highly entertaining event. At the dinner, we enjoyed a wonderful meal, had an opportunity to explore the Hall, and experienced an interactive music therapy presentation and a scavenger hunt. A great time was had by all. I look forward to seeing you next year in Atlanta, GA, from October 3 to 5, 2018. Keep an eye on the Association website (aaceonline.com) for meeting updates.

Finally, congratulations to Dr. John Vetto, our Deputy Editor, who was awarded the Dr. Margaret Hay Edwards Award for meritorious service to the field of cancer education! Well done!!!

Arthur M. Michalek, PhD, FACE 